\title{
Family, social, and cultural factors in pedestrian injuries among Hispanic children
}

\author{
Phyllis F Agran, Diane G Winn, Craig L Anderson, Celeste Del Valle
}

\begin{abstract}
Objectives-In an earlier population based surveillance study of pediatric injuries, the rate of Hispanic children injured as pedestrians was $63 / 100000$ compared with $17 / 100000$ for non-Hispanic white children. The present study was designed to examine the effect of family, social, and cultural factors on the rate of pedestrian injury in a population of Hispanic children in the southwestern US.

Methods-A case-control study of pedestrian injuries among Hispanic children. The sample consisted of 98 children 0-14 years of age hospitalized as a result of a pedestrian injury and 144 randomly selected neighborhood controls matched to the case by city, age, gender, and ethnicity. Cases were compared with controls using conditional logistic regression; in the study design the odds ratio (OR) estimates the incidence rate ratio.
\end{abstract}

Results-The following family and cultural variables were associated with an increased risk of injury: household crowding $(O R=2.8,95 \%$ confidence interval $(C I)$ 1.1 to 7.1 for $1.01-1.5$ persons per room, compared with $\leqslant 1.0$ persons per room), one or more family moves within the past year (OR 2.2, 95\% CI 1.2 to 4.1 ), poverty (OR 1.9, 95\% CI 1.1 to 3.3), and inability of mother (OR 3.6, 95\% CI 1.3 to 10 ) or father (OR 5.6, 95\% CI 1.5 to 20 ) to read well. However, children in single parent households and children whose parents did not drive a car, had less education, or were of rural origin, did not have an increased rate of injury.

Conclusions-These results have implications for childhood pedestrian prevention efforts for low income, non-English speaking Hispanic populations, and perhaps for other immigrant and high risk groups. Prevention programs and materials need to be not only culturally sensitive but also designed for those with limited reading skills. In addition, environmental interventions that provide more pedestrian friendly neighborhoods must be considered.

(Injury Prevention 1998;4:188-193)

Keywords: pedestrian injury; Hispanic; family; social

Pedestrian injuries are a significant source of morbidity, mortality, and disability among children. In several industrialized countries, pedestrian injuries are a leading cause of childhood death and hospitalization. ${ }^{1-5}$ Moreover, the number of such injuries may be underestimated because of incomplete data and/or exclusion of certain types of pedestrian events (that is non-traffic) from some databases. ${ }^{6-11}$ Less is known about pedestrian injuries in developing countries, but child pedestrian death rates in some of those countries are reportedly many times greater than rates in industrialized countries. ${ }^{12}$

Several social and economic indicators have been identified as risk factors for childhood pedestrian injury. Poverty and unemployment have been associated with a higher rate of pedestrian injury to children. ${ }^{13-21}$ Crowding, whether measured as household crowding ${ }^{142022}$ or as neighborhood population density, ${ }^{16}{ }^{17}$ has also been associated with such injuries. In addition, Rivara and Barber found a higher proportion of non-whites in the census tracts with higher rates of pediatric pedestrian injuries in a southern US city. ${ }^{14}$ Parent variables, including single parent households, ${ }^{131416171920}$ young mothers, ${ }^{19}$ low levels of education, ${ }^{13} 1420$ and stress and lack of support $^{22}$ are also risk factors. Children in families with many children have more pedestrian injuries than children in families with fewer children. ${ }^{19}$ Areas with high measures of social disadvantage, including crime, ${ }^{17}$ family problems, and poor health, ${ }^{18}$ also have higher rates of pedestrian injury. Many of these factors are interrelated, and in multivariate analyses, the effects of low income ${ }^{13}$ and household crowding ${ }^{14}$ have been shown to be independent of other social variables.

Other social variables have been associated with the rate of injury to children but their specific association with pedestrian injuries has not been investigated. Both changes in residence and the occurrence of stressful life events have been related to increased risk for injury. ${ }^{23}{ }^{24}$ Birth order has also been found to influence the effect of family size on the rate of injury - the presence of older siblings has a greater effect on the injury rate than the presence of younger siblings. ${ }^{25}$ Larson and Pless found that the absence of a younger sibling, as well as maternal smoking and unemployment, were risk factors for injury in the first three years of life. ${ }^{26}$

Although several studies have investigated family and social risk factors for child pedestrian injury ${ }^{13-18} 20-22$ using group level data, only two studies have examined individual data. Roberts found that socioeconomic disadvantage, large families, younger mothers, no access to a car, and, for some ethnic groups, single parent households, were risk factors for pedestrian injury. ${ }^{19}$ Pless and his associates, also 
using individual data, found that low maternal education and four or more children in a family were risk factors for pedestrian and bicyclist injuries combined. ${ }^{27}$ There has been no study of social risk factors for pedestrian injury at the individual level in the US however, nor has the effect of these socioeconomic indicators been examined in a Hispanic population.

Our earlier research found that Hispanic children have a rate of hospitalization or death from pedestrian injury that is more than twice as high as the rate in non-Hispanic white children, controlling for census block group of residence. ${ }^{28}$ The purpose of the present study is to examine the effect of family, social, and cultural factors on the rate of pedestrian injury in a population of Hispanic children in the southwestern US. A case-control design was used to compare Hispanic children age $0-14$ years who were hospitalized for pedestrian injuries with controls matched on age, sex, ethnicity, and city of residence.

\section{Methods}

Cases were identified from a population based hospital surveillance system established in central Orange County, California to identify children less than 15 years of age who sustained injuries resulting in hospitalization or death. The study area consisted of seven cities (Santa Ana, Anaheim, Fountain Valley, Garden Grove, Orange, Villa Park, and Tustin), and one census designated place (Tustin Foothills). The study population consisted of 213906 children aged $0-14$ years; $49 \%$ were Hispanic, $37 \%$ were non-Hispanic white, $12 \%$ were Asian or Pacific Islander, 2\% were black, and fewer than $1 \%$ were Native American or any other race. Eighty seven per cent of the Hispanic population of the study area is of Mexican descent.

Because the pedestrian injury rate for Hispanic children was more than twice that of non-Hispanic white children (controlling by census block group), the case-control study was designed to include only Hispanic children. Hispanic children were defined as those with one or two parents who identified themselves as Hispanic or Latino.

The cases were all Hispanic children age 0-14 years hospitalized as a result of a pedestrian injury caused by conflict with a motor vehicle from 1 July 1991 through 30 June 1993. Children operating a pedestrian conveyance, such as roller skates, a skateboard, or a tricycle (but not a bicycle) were also included. The parent or guardian of the injured child was contacted and interviewed in the hospital or in the child's home by one bilingual interviewer.

One control was obtained for each case; a second control was obtained if an appropriate subject was identified within one month of the injury event. Controls had to have one or two Hispanic parents, and were matched to the case by city, age or year of birth, and gender. A census tract (weighted by the number of Hispanic residents), census block, and starting residence were randomly selected for each control. A bilingual interviewer began at the starting residence and proceeded clockwise around the block until a control was obtained. If necessary, additional blocks were selected and canvassed. If no match was found after 95 residences were canvassed, another census tract was selected.

Single parent households were defined as in the census, that is as those in which a parent had no spouse in the household. Thus, the category of "single parent" included widowed, separated, divorced, or never married parents. Comparisons based on this variable excluded children not living with either parent.

Poverty was defined using family income and the number of people it supported. The income levels used to define poverty in the 1990 census were rounded off to increments used in our question on annual family income. These increments were in the amount of $\$ 2500$ up to $\$ 15000$, and $\$ 5000$ increments for annual incomes $\$ 15000$ to $\$ 35000$. For example, for a two person family, poverty was defined as an income of less than $\$ 7500$. The threshold for poverty increased by $\$ 2500$ for each additional person. The family income question did not specify whether public assistance should be included in the total, and therefore it is not known how many included this in their answers.

To measure family stress, respondents were asked whether they or their children had experienced any of 16 different life change events during the previous year. These events were drawn from a Stressful Life Events scale that has been culturally validated with MexicanAmerican and Mexican immigrant women. ${ }^{29}$ Two variables were used as indicators of social support: how often the respondents said they could depend on family and friends to help with errands and household tasks, and the number of adult relatives (other than the child's parent or guardian) they had in the household.

Comparisons based on parental characteristics excluded parents not living in the same household as the child, but the responses of six female guardians or stepmothers and nine male guardians or stepfathers living in the household were included as parent responses.

The number of years since the mother first arrived in the US was used to measure the recency of immigration. Rural origin was defined as having lived in the country (campo) or a village (pueblo) in the country of origin and having immigrated to the US at age 12 years or older. Parents were classified as "not reading well" if they reported reading neither English or Spanish "somewhat", "not very well", or "not at all" (as opposed to "very well").

ANALYSIS

The effects of the various family and cultural factors on the rate of pedestrian injury were estimated using conditional logistic regression in the Egret interactive modeling package (Statistics and Epidemiology Research Corporation, Seattle). Because incident cases were used and the controls were identified contemporaneously, the odds ratios may be 
Table 1 Number (\%) of cases $(n=98)$ and of controls $(n=144)$, crude odds ratio (OR), 95\% confidence interval (CI), and $p$ values for variables describing household

\begin{tabular}{|c|c|c|c|c|c|c|}
\hline Variable & Range & Cases No (\%) & Controls No (\%) & $O R$ & $95 \% C I$ & $p$ Value \\
\hline Single parent ${ }^{\star}$ & & $43(45)$ & $43(30)$ & 1.6 & $1.0-2.7$ & 0.06 \\
\hline Poverty & & $60(61)$ & $66(46)$ & 1.9 & $1.1-3.3$ & 0.02 \\
\hline Household & $\leqslant 1.00$ per room & $7(7)$ & $29(20)$ & 1.0 & Reference & 0.02 \\
\hline \multirow{3}{*}{ crowding } & $1.01-1.50$ per room & $25(26)$ & $35(24)$ & 2.8 & $1.1-7.1$ & \\
\hline & $1.51-2.00$ per room & $28(29)$ & $44(31)$ & 2.9 & $1.1-7.7$ & \\
\hline & $>2.00$ per room & $38(39)$ & $36(25)$ & 3.7 & $1.5-9.1$ & \\
\hline \multirow[t]{3}{*}{ Household size } & 3-6 persons & $30(31)$ & $50(35)$ & 1.0 & Reference & 0.70 \\
\hline & 7-9 persons & $35(36)$ & $51(35)$ & 1.2 & $0.7-2.2$ & \\
\hline & 10 or more persons & $33(34)$ & $43(30)$ & 1.3 & $0.7-2.4$ & \\
\hline \multirow{3}{*}{$\begin{array}{l}\text { Full time working } \\
\text { parent(s)/guardian } \dagger\end{array}$} & None & $42(43)$ & $42(29)$ & 1.0 & Reference & 0.06 \\
\hline & One & $40(41)$ & $73(51)$ & 0.5 & $0.3-0.9$ & \\
\hline & Two & $16(16)$ & $29(20)$ & 0.5 & $0.2-1.1$ & \\
\hline Moves in the last year & $\geqslant 1$ move & $40(41)$ & $38(26)$ & 2.2 & $1.2-4.1$ & 0.007 \\
\hline Moves $1-5$ years ago & $\geqslant 1$ move & $78(80)$ & $104(72)$ & 1.5 & $0.8-2.8$ & 0.15 \\
\hline \multirow[t]{3}{*}{ Life events } & 0 or 1 event & $27(28)$ & $52(36)$ & 1.0 & Reference & 0.51 \\
\hline & 2 or 3 events & $37(38)$ & $47(33)$ & 1.4 & $0.8-2.5$ & \\
\hline & 4 or more events & $34(35)$ & $45(31)$ & 1.4 & $0.7-2.7$ & \\
\hline \multirow{3}{*}{$\begin{array}{l}\text { Depend on friends and } \\
\text { family to help with } \\
\text { errands, tasks or ride }\end{array}$} & Never & $30(31)$ & $57(40)$ & 1.0 & Reference & 0.20 \\
\hline & Sometimes & $43(44)$ & $45(31)$ & 1.6 & $0.9-2.9$ & \\
\hline & Always & $25(26)$ & $42(29)$ & 1.0 & $0.5-1.9$ & \\
\hline \multirow{3}{*}{$\begin{array}{l}\text { Other related adults in } \\
\text { household }\end{array}$} & 0 & $34(35)$ & $61(42)$ & 1.0 & Reference & 0.67 \\
\hline & 1 & $39(40)$ & $47(33)$ & 1.3 & $0.7-2.4$ & \\
\hline & 2 or more & $25(26)$ & $36(25)$ & 1.2 & $0.6-2.3$ & \\
\hline
\end{tabular}

ॠExcludes two cases and three controls not living with either parent. Single parents $(n=86)$ include the following: unmarried but live with child's parent, $34(40 \%)$ ( 16 cases, 18 controls); live with other family members, $32(37 \%)$ (18 cases, 14 controls); live with other adults, 13 (15\%) (seven cases, six controls); no other adults in household, seven (8\%) (two cases, five controls).

tOf the 84 families with no full time working parents: no parent works, 55 (65\%) (29 cases, 26 controls); one or both parents work part time, 29 (35\%) (13 cases, 16 controls).

interpreted as estimates of the incidence rate ratios. ${ }^{30}$ Multivariate models were compared with the likelihood ratio statistic, which has a $\chi^{2}$ distribution. Odds ratios and confidence intervals were calculated comparing the range of each continuous variable to the lowest range; $p$ values were obtained from the likelihood ratio statistic.

\section{Results}

A total of 112 Hispanic children were injured as pedestrians, five of whom were killed. Consent for interview was obtained from the parent/guardian of $98(92 \%)$ of the 107 non-fatally injured children. The nine cases for which no consent was obtained included a higher proportion of older children (age 5-14 years) and a lower proportion of Santa Ana residents than cases that were interviewed.
The characteristics of the 98 cases for which an interview was conducted are as follows: one case was less than 1 year of age; 57 were $1-4$ years; 33 were 5-9; and 7 were age 10-14. Seventy were boys. Sixty one of the injuries occurred from $3 \mathrm{pm}$ to $9 \mathrm{pm}$, and 38 occurred on a Friday or Saturday. Sixty nine children were injured in a street and 25 in a parking lot or driveway, or on a sidewalk. Each case had at least one matched control and $47 \%$ also had a second matched control, making a total of 144 controls. Almost all of the case and control interview respondents were mothers.

Several variables describing the child's household are shown in table 1. Children from single parent households were not at significantly increased risk for injury. Children who lived in families with incomes below the poverty level, however, had nearly twice the

Table 2 Number (\%) of cases ( $n=98)$ and of controls ( $n=144)$, crude odds ratio (OR), 95\% confidence interval (CI), and $p$ values parent and child variables

\begin{tabular}{|c|c|c|c|c|c|c|}
\hline Variable & Range & Cases No (\%) & Controls No (\%) & $O R$ & $95 \% C I$ & $p$ Value \\
\hline \multirow[t]{3}{*}{ Birth order of child } & First & $29(30)$ & $54(38)$ & 1 & Reference & 0.67 \\
\hline & Second & $30(31)$ & $38(26)$ & 1.3 & $0.7-2.6$ & \\
\hline & Third or later & $39(40)$ & $52(36)$ & 1.2 & $0.7-2.2$ & \\
\hline Child not speak English` & & $62(63)$ & $73(51)$ & 2.1 & $1.1-3.7$ & 0.02 \\
\hline Mother not speak English $\dagger$ & & $62(64)$ & $95(66)$ & 1.0 & $0.6-1.7$ & 0.96 \\
\hline Father not speak English $\neq$ & & $47(64)$ & $57(47)$ & 2.2 & $1.0-4.6$ & 0.03 \\
\hline \multirow[t]{3}{*}{ Mother's education $\dagger$} & $0-5$ years & $29(30)$ & $31(22)$ & 1.0 & & 0.31 \\
\hline & $6-9$ years & $37(38)$ & $62(43)$ & 0.6 & $0.3-1.2$ & \\
\hline & 10 or more years & $31(32)$ & $50(35)$ & 0.6 & $0.3-1.2$ & \\
\hline \multirow[t]{3}{*}{ Father’s education $\ddagger$} & $0-5$ years & $26(35)$ & $29(24)$ & 1.0 & Reference & 0.54 \\
\hline & $6-9$ years & $32(43)$ & $57(47)$ & 0.7 & $0.3-1.5$ & \\
\hline & 10 or more & $16(22)$ & $35(29)$ & 0.6 & $0.3-1.5$ & \\
\hline Mother not read well $\dagger$ & & $15(15)$ & $11(8)$ & 3.6 & $1.3-10$ & 0.01 \\
\hline Father not read well & & $16(22)$ & $6(5)$ & 5.6 & $1.5-20$ & 0.003 \\
\hline \multirow{3}{*}{$\begin{array}{l}\text { Years since mother came } \\
\text { to USt }\end{array}$} & US born & $15(15)$ & $23(16)$ & 1.0 & Reference & 0.76 \\
\hline & $\geqslant 10$ & $37(38)$ & $60(42)$ & 1.0 & $0.5-2.2$ & \\
\hline & $0-9$ years & $45(46))$ & $60(42))$ & 1.2 & $0.6-2.6$ & \\
\hline Mother does not drive $\nmid$ & & $58(60)$ & $69(48)$ & 1.6 & $0.9-2.6$ & 0.09 \\
\hline Father does not drive $\ddagger$ & & $8(11)$ & $8(7)$ & 0.6 & $0.2-2.0$ & 0.43 \\
\hline Mother of rural origin $†$ & & $35(36)$ & $51(36)$ & 1.0 & $0.5-1.7$ & 0.88 \\
\hline Father of rural origin $\ddagger$ & & $27(36)$ & $49(40)$ & 0.7 & $0.4-1.3$ & 0.29 \\
\hline \multirow[t]{2}{*}{ Mother's age } & $18-24$ years & $26(27))$ & $31(22)$ & 1.0 & Reference & 0.34 \\
\hline & $\geqslant 25$ years & $71(73))$ & $112(78)$ & 0.7 & $0.4-1.4$ & \\
\hline
\end{tabular}

^Excludes one control child, age 8 months, who did not talk.

†Excludes one case and one control not living with mother, stepmother, or female guardian.

¥Excludes 24 cases and 23 controls not living with father, stepfather, or male guardian. 
Table 3 Odds ratio (OR), adjusted for other variables shown, 95\% confidence interval $(C I)$, and $p$ values for selected variables $(n=236)$ *

\begin{tabular}{lllll}
\hline Variable & Range & Adjusted OR & $95 \%$ CI & p Value \\
\hline Household crowding & $\geqslant 1.01$ per/room & 3.0 & $1.2-7.7$ & 0.01 \\
Mother does not read well & $\geqslant 1$ move & 3.9 & $1.2-12$ & 0.02 \\
Moves in the last year & 2.2 & $1.2-4.3$ & 0.01 \\
\hline
\end{tabular}

${ }^{\star}$ Excludes three cases and three controls not living with either parent, or not living with a mother, stepmother, or female guardian.

frequency of pedestrian injury as those who did not. Children in households with more than one person per room also had a significantly higher risk, but those in larger households (more people per household) did not. Nor was employment status of the parents related to an increased injury rate.

Variables related to family change, stress, and social support were also examined. Children whose families had made one or more moves in the last year had twice the frequency of pedestrian injury as those whose families had not moved. Moves one to five years in the past were not associated with pedestrian injury, nor was the number of stressful life events or either indicator of social support.

Child and parent characteristics are displayed in table 2. Children who did not speak English had about twice the incidence of injury of children who spoke English, but inability to speak English was closely related to age: $67 \%$ of children $0-5$ years, but only $28 \%$ of school age children, did not speak English. Children of fathers, but not mothers, who did not speak English had an increased incidence of pedestrian injury. Children whose parents were unable to read well had more than three times the incidence of injury compared with children whose parents could read either English or Spanish well. However, the extent of parents' formal education was not associated with the incidence of pedestrian injury, nor was injury related to mother's age or duration of residence in the US, or to the rural origin or driving of either parent.

Three variables found to be significantly related to injury were selected for inclusion in a multivariate model (table 3): household crowding, mother not reading well, and one or more moves in the last year. (Poverty was not included because it is closely related to household crowding.) One level of household crowding was included because the three levels of crowding in table 1 had similar odds ratios. Speaking English was not kept in the model because other variables, such as duration of residence in the US and employment, may be related to learning a language. The adjusted odds ratios for household crowding, mother does not read well, and moves in the last year (table 3) were similar to the crude odds ratios in tables 1 and 2.

\section{Discussion}

Despite advances in traffic safety, pedestrian injuries remain a leading cause of mortality, morbidity, and disability for children in many countries. ${ }^{1-5} 313233$ Several studies in the US, Canada, New Zealand, Australia, and other countries have identified populations at in- creased risk for childhood pedestrian injuries. ${ }^{13-2034}$ High neighborhood levels of poverty and crowding have repeatedly been identified as risk factors.

In our previous study Hispanic children in California were found to have rates of hospitalization/death for pedestrian injury more than three times that of non-Hispanic white children. ${ }^{28}$ Even after controlling for census block group of residence, these rates remained twice as high, indicating that the differences could not be explained entirely by the neighborhood physical and socioeconomic environment.

The present study, a case-control study of pedestrian injuries in the same population of Hispanic children, found several risk factors similar to other studies (that is household crowding, poverty). However, other risk factors identified in those studies (that is lesser education, greater stress, not driving a car, single parent), were not found to be significantly related to these injuries, possibly because of the composition of our study population. Most children were poor, lived in crowded households, had non-English speaking mothers who did not drive, and had parents with fairly high levels of unemployment. In this southwestern Hispanic population, however, a number of other family and sociocultural factors (that is functional literacy, at least one move in the past year, and father not speaking English) were found to be significantly related to pedestrian injuries.

\section{SPECIFIC RISK FACTORS}

The strongest risk factor for injury identified in this study was having parents who reported that they did not read well in either language (Spanish or English), although the number of these parents was small. In other studies, illiteracy and low literacy have been found to be associated with poisoning as well as generally higher mortality and poor health status. ${ }^{35} 36$ The increased rate found in this study was not the result of the other variables included in the multivariate model.

Children in families with frequent moves have been found to be at increased risk for injury. $^{2037}$ Moving in the past year was a significant risk factor in this study, as well. Moves one to five years in the past, however, were not associated with injury. Families who have recently moved may be less familiar with their new environment, placing them at higher risk. Additionally, these families may have higher levels of stress as well as less interaction with, and support from, their neighbors. Although almost all of the moves in this study were within the same country, these families may experience stresses similar to immigrant families relocating to the US. ${ }^{38}$

As has been found in other studies, both poverty and household crowding were associated with pedestrian injury among Hispanic children in this study. In a previous study in this population, which used census block group data, neighborhood levels of crowding were not associated with injuries to Hispanic children. ${ }^{39}$ The effect of crowding may be specific to 
pedestrian injuries or household crowding may be more important at the individual level rather than at the neighborhood level. Even though in the traditional Mexican house, all the space is used for multiple activities by family members and guests, and close contact among family members is common, ${ }^{40}$ there may be some critical level of crowding that increases the risk for injury. Also children in crowded households may spend more time outdoors, thereby increasing exposure.

Spanish was the predominant language spoken in this study population. Speaking English had different effects on the risk for injury for various members of the family. We found a significantly higher rate of childhood pedestrian injuries among children who did not speak English and those of fathers, but not mothers, who did not speak English. This was unexpected, because we believe that mothers play a major part in preventing injuries to children. Possibly the homogeneity of the mothers with regard to speaking only Spanish may have masked the effects associated with speaking English. Language is an important measure of acculturation ${ }^{41}$ and differences in language may be accompanied by differences in parenting practices, as well as by access to sources of information on health hazards. The higher injury rate for non-English speaking children reflects the fact that most injuries occurred in preschoolers, and the majority of preschool children did not speak English, while the majority of older children did. Injury rate differentials between children whose fathers who did and did not speak English also may be a result of the greater economic opportunities open to fathers who speak English.

An unexpected finding was that children of single parents were not found to be at increased risk for pedestrian injury in this Hispanic population. Others have found that single parenthood is related to other socioeconomic factors as well as lack of supportive networks. ${ }^{42}$ Similar to the Pacific Islanders in Roberts' study in New Zealand, ${ }^{19}$ this Hispanic population may have extended family networks and social supports that provide beneficial effects to children in single parent households. A single parent was the only adult in fewer than $4 \%$ of the households. The majority of single parents lived either unmarried with the child's other parent or with other family members. In the case of pedestrian injury, more adults may mean more child care takers and thereby increased supervision.

\section{LIMITATIONS}

Because of the choice of study population, results of this analysis may not apply to other populations. Fifty nine per cent of the cases were less than 5 years old. If the effect of risk factors varies with the age of the child, the factors identified here may not apply to populations with a greater proportion of older children. Further, this study was limited to Hispanic children in the southwestern US, and the risk factors identified may not apply to other populations. Focusing on Hispanic children, however, enabled us to examine variables such as language and other sociocultural issues that are relevant to immigrant communities in general.

The way the controls were identified may also have resulted in some biases. Controls were selected using a door to door search to include households without telephones. However, respondents were probably aware that they could end the interview by stating that no children lived at that residence. It is not possible to measure any selection bias introduced by such refusals.

\section{Implications for prevention}

The results of this study have important implications for prevention activities for this population and also perhaps for other populations with similar sociocultural risk factors for childhood pedestrian injuries.

First and foremost, educational materials and programs should be in the language(s) used by the community. Of note, nearly two thirds of the mothers in our study spoke only Spanish and most injury prevention materials are in English. ${ }^{43-45}$ Culturally and linguistically appropriate messages must be developed and tested with the specific audiences for whom they are intended.

In communities such as that in our study, where many parents have little formal education, messages must be presented simply. Although only a small proportion of the parents in this study reported that they did not read well, this was the strongest risk factor for injury. Children of such parents had a three times greater risk of pedestrian injury than did children whose parents were good readers. Therefore, safety messages using techniques other than the written word should be considered. Less acculturated Hispanics have been found to have less access and contact with the health care system, especially for preventive services, indicating that there is a need to consider other approaches to reach this high risk population. ${ }^{46}{ }^{47}$ Community health workers, as well as the visual media, have been found to be preferred methods for delivery of prevention messages for many Spanish speaking populations in the US..$^{48-52}$

As one of the strongest risk factors in this population was a family move within the past year, it is important to consider environmental interventions that would provide a more pedestrian friendly neighborhood into which people move. Such measures should be ongoing and institutionalized so that they are less dependent on individual behaviors. Environmental changes that reduce street side parking as well as calm traffic to reduce its speed and volume have been recommended by a number of researchers to make residential streets less hazardous for children. ${ }^{125354}$

This research was supported by grant R49-CCR-904406 from the Centers for Disease Control and Prevention. The contents are solely the responsibility of the authors and do not necessarily represent the official views of the National Center for Injury ily represent the official
Prevention and Control. 
1 Rivara FP. Child pedestrian injuries in the United States. Current status of the problem, potential interventions, and future research needs. Am f Dis Child 1990;144:6

2 Stevenson MR, Sleet DA. Which prevention strategies for child pedestrian injuries? A review of the literature. International Quarterly of Community Health Education 1997;16:207-17.

Roberts IG. International trends in pedestrian injury mortality. Arch Dis Child 1993;68:190-2.

4 Fingerhut LA, Annest JL, Baker SP, et al. Injury mortality among children and teenagers in the United States, 1993. Inj Prev 1996;2:93-4.

5 Preston B. Child pedestrian fatalities: the size of the problem and some suggested countermeasures. Fournal of Advanced Transportation 1994;28:129-40.

6 Agran PF, Castillo DN, Winn DG. Limitations of data compiled from police reports on pediatric pedestrian and bicycle motor vehicle events. Accid Anal Prev 1990;22:361-70.

7 Teanby D. Underreporting of pedestrian road accidents. BMF 1992;304:422

8 Stevenson MR, Lo SK, Laing BA, et al. Childhood pedestrian injuries in the Perth metropolitan area. Med $\mathcal{F}$ Aust 1992;156:234-8.

9 Winn DG, Agran PF, Castillo DN. Pedestrian injuries to children younger than 5 years of age. Pediatrics 1991;88 776-82.

10 Brison RJ, Wicklund K, Mueller BA. Fatal pedestrian injuries to young children: a different pattern of injury. $A \mathrm{~m}^{-}$ Public Health 1988;78:793-5.

11 Roberts I, Kolbe A, White J. Non-traffic child pedestrian injuries. F Paediatr Child Health 1993;29:233-4.

12 Preston B. Cost effective ways to make walking safer for children and adolescents. Inj Prev 1995;1:187-90.

13 Durkin MS, Davidson LL, Kuhn L, et al. Low-income neighborhoods and the risk of severe pediatric injury: a small-area analysis in northern Manhattan. Am $\mathcal{F}$ Public Health 1994;84:587-92.

14 Rivara FP, Barber M. Demographic analysis of childhood pedestrian injuries. Pediatrics $1985 ; 76: 375-81$.

pedestrian injuries. Pediatrics 1985;76:375-81.
15 Dougherty G, Pless IB, Wilkins R. Social class and the occurrence of traffic injuries and deaths in urban children. Can F Public Health 1990;81:204-9.

16 Braddock M, Lapidus G, Gregorio D, et al. Population, income, and ecological correlates of child pedestrian injury. Pediatrics 1991;88:1242-7.

17 Bagley C. The urban setting of juvenile pedestrian injuries: a study of behavioural ecology and social disadvantage. Accid Anal Prev 1992;24:673-8.

18 Kendrick D. Prevention of pedestrian accidents. Arch Dis Child 1993;68:669-72.

19 Roberts I. Sole parenthood and the risk of child pedestrian injury. F Paediatr Child Health 1994;30:530-2.

20 Joly MF, Foggin PM, Pless IB. Geographical and socioecological variations of traffic accidents among children. Soc Sci Med 1991;33:765-9.

21 Mueller BA, Rivara FP, Lii SM, et al. Environmental factors and the risk for childhood pedestrian-motor vehicle collision occurrence. Am 7 Epidemiol 1990;132:550-60.

22 Christoffel KK, Donovan M, Schofer J, et al. Psychosocial factors in childhood pedestrian injury: a matched casecontrol study. Kids and Car Team. Pediatrics 1996;97:3342.

23 Beautrais AL, Fergusson DM, Shannon FT. Childhood accidents in a New Zealand birth cohort. Aust Paediatr $\mathcal{F}$ 1982;18:238-42.

24 Harris MJ, Kotch JB. Unintentional infant injuries: sociodemographic and psychosocial factors. Public Health Nurs 1994;11:90-7.

25 Bijur PE, Golding J, Kurzon M. Childhood accidents, family size, and birth order. Soc Sci Med 1988;26:839-43.

26 Larson CP, Pless IB. Risk factors for injury in a 3-year birth cohort. Am f Dis Child 1988;142:1052-7.

27 Pless IB, Verreault R, Tenina S. A case-control study of pedestrian and bicyclist injuries in childhood. Am f Public Health 1989;79:995-8

28 Agran PF, Winn DG, Anderson CL. Pediatric injury hospitalization in Hispanic and non-Hispanic white children in talization in Hispanic and non-Hispanic white children in 400-6.

29 Zambrana RE, Scrimshaw SC, Collins N, et al. Prenatal health behaviors and psychosocial risk factors in pregnant women of Mexican origin: the role of acculturation. Am $\mathscr{f}$ Public Health 1997;87:1022-6.
30 Greenland S, Thomas DC. On the need for the rare disease assumption in case-control studies. Am $\mathcal{f}$ Epidemiol 1982;116:547-53.

31 Pardo JM. The exposure of Spanish children to accident risk as pedestrians. In: Rothengatter T, de Bruin R, eds. Road user behavior: theory and research. Netherlands: Van Gorcum, 1988 .

32 Jorgensen IM. Fatal unintentional child injuries in Denmark. Dan Med Bull 1996;43:92-6.

33 Bass D, Albertyn R, Melis J. Child pedestrian injuries in the Cape metropolitan area-final results of a hospital-based study. $S$ Afr Med 7 1995;85:96-9.

34 Stevenson MR, Jamrozik KD, Spittle J. A case-control study of traffic risk factors and child pedestrian injury. Int $\mathcal{f} E p i-$ demiol 1995;24:957-64.

35 Mrvos R, Dean BS, Krenzelok EP. Illiteracy: a contributing factor to poisoning. Vet Hum Toxicol 1993;35:466-8.

36 Weiss BD, Blanchard JS, McGee DL, et al. Illiteracy among Medicaid recipients and its relationship to health care costs. Health Care Poor Underserved 1994;5:99-111.

37 Wadsworth J, Burnell I, Taylor B, et al. Family type and accidents in preschool children. $\mathcal{f}$ Epidemiol Community Health 1983;37:100-4.

38 Saba GW. Immigration, acculturation, and stress: a family-systems approach. Report of the twenty-fifth Ross roundtable on critical approaches to common pediatric problems in collaboration with the Ambulatory Pediatric Association. Columbus, OH: Ross Products Division, Abbott Laboratories, 1995:116-32.

39 Anderson CL, Agran PF, Winn DG, et al. Demographic risk factors for injury among Hispanic and non-Hispanic white children: an ecologic analysis. Inj Prev 1998;4:33-8.

40 Pader EJ. Spatiality and social change: domestic space use in Mexico and the United States. American Ethnologist 1993;20:114-37.

41 Marin G, Sabogal F, VanOss-Marin B, et al. Development of a short acculturation scale for Hispanics. Hispanic fournal of Behavioral Science 1987;9:183-205.

42 Judge $\mathrm{K}$, Benzeval $\mathrm{M}$. Health inequalities new concerns about the children of single mothers. BMF 1993;306:67780 .

43 Doak CC, Doak LG, Root JH. Teaching patients with low literarcy skills. Philadelphia, PA: JB Lippincott, 1985.

44 Aguirre-Molina M, Ramirez A, Ramirez M. Health promotion and disease prevention strategies. Public Health Rep 1993;108:559-64.

45 US Department of Transportation, National Highway Traffic Safety Administration. Study identifies traffic safety needs of Hispanic groups. Technology Transfer Series. Washington, DC: NHTSA, 1996.

46 Olds DL, Kitzman H. Can home visitation improve the health of women and children at environmental risk? Pediatrics 1990;86:108-9.

47 Zambrana RE, Ell K, Dorrington C, et al. The relationship between psychosocial status of immigrant Hispanic mothers and use of emergency pediatric services. Health Soc Work 1994;19:93-102.

48 Wittenberg CK. Summary of market research for "Healthy Mothers, Healthy Babies" campaign. Public Health Rep 1983;98:356-9.

49 Powell DR, Zambrana R, Silva-Palacios V. Designing culturally responsive parent programs: a comparison of low-income Mexican and Mexican-American mothers' preferences. Family Relations 1990;39:298-304.

50 Warrick L, Christianson JB, Walruff $\mathrm{F}$, et al. Educational outcomes in teenage pregnancy and parenting programs: results from a demonstration. Fam Plann Perspect 1993;25: $148-55$

51 Bray ML, Edwards LH. A primary health care approach using Hispanic outreach workers as nurse extenders. Public Health Nurs 1994;11:7-11.

52 Romer D, Kim S. Health interventions for African American and Lationo youth: the potential role of mass media. Health Educ Q 1995;22:172-89.

53 Roberts I, Norton R, Jackson R, et al. Effect of environmental factors on risk of injury of child pedestrians by motor vehicles: a case-control study. BMF 1995;310:91-4.

54 Agran PF, Winn DG, Anderson CL, et al. The role of the physical and traffic environment in child pedestrian injuries. Pediatrics 1996;98:1096-103. 